\title{
The Effects of Drought on Crop Yields and Yield Variability: An Economic Assessment
}

\author{
Inoussa Boubacar \\ Correspondence: Inoussa Boubacar, Social Science Department, University of Wisconsin Stout, Menomonie, WI, \\ 54751, USA. Tel: 1-715-232-1509. E-mail: boubacari@uwstout.edu
}

\author{
Received: March 27, $2012 \quad$ Accepted: October 15, $2012 \quad$ Online Published: October 26, 2012 \\ doi:10.5539/ijef.v4n12p51 URL: http://dx.doi.org/10.5539/ijef.v4n12p51
}

\begin{abstract}
Sahel is a drought-prone area in West Africa, and the agriculture sector remains the main source of employment in the rural communities. However, inter-annual rainfall variability significantly hampers the performance of agriculture in Sahel. Over the past four decades, drought episodes have been the norm rather than the exception in the region. Using a just-Pope stochastic production function, this paper assesses crop yields responses to persistent drought spells in eight countries of Sahel. Six-month standardized precipitation indexes (SPI) along with degree-days indexes were calculated and maximum likelihood estimations were carried out for specific crops using data spanning 1970 to 2000 . The results show that while an increase in the degree-days tends to be harmful to crop yields, SPI and precipitation intensity index have statistically positive impacts on the mean crop yields. The adaptation to climate variability suggests a modernization of the farming techniques such as the reliance on irrigated agriculture.
\end{abstract}

Keywords: crop yield, Sahel, SPI, stochastic model, vulnerability

\section{Introduction}

The far reaching devastating effects of global warming have catalyzed an economic rethinking of climate change debates. While empirical evidence shows that the increased emission of greenhouse gases is the main cause of the ongoing changes in climate conditions, recent studies provide significant evidence that the burdens on the societies will differ across regions. In effect, on the onset of the global increase in temperature, some areas will face an irregularity and a reduction in rainfall, whereas other parts of the globe will have to deal with an increase in the number of tornadoes, a rise in floods and prevalence of hurricanes (Houghton, Meiro-Filho, Callandar and Harris, 1996; Schimmelpfennig and Yohe, 1999). Various studies (Intergovernmental Panel on Climate Change [IPCC], 2007) pinpoint Africa as one of the most exposed continents to suffer the worst devastating effects of climate change and climate variability, with colossal economic consequences. The African rain-fed agriculture is viewed by many observers as the most vulnerable sector to climate variability. A number of African countries structurally experience semi-arid conditions worsened by a staggered agricultural productivity and a reliance on import of foodstuffs. IPCC (2007) predicts a reduction of 50 percent in yield by 2020, and a fall in crop net revenues of 90 percent by 2100 in already struggling regions. If these dismal predictions come to realization, then most countries in Sahel will cease agricultural production. The purpose of this paper is to analyze the effects of droughts on the mean and variance of crop yields, and to examine the implications of climate variability on agriculture in eight countries of Sahel. I estimate stochastic production functions by regressing crop yields on precipitation, temperature and land variables. One of the strengths of this paper is the use of the Standardized Precipitation Index (SPI) and the precipitation intensity index to account for droughts and rainfall variability and the inclusion of the degree-days to capture the effects of temperature on crop yields. (Note 1) Hence, this study will contribute to the existing literature on impact studies of climate variability. The econometric model reveals that an increase in temperatures and a poor spread of rainfall throughout the growing season have a damaging impact on the mean of crop yields; and simultaneously, an increase in precipitation (or a reduction in the severity of drought) is beneficial to crop yields. Furthermore, I find significant evidence to conclude that precipitation and temperature are risk-increasing in maize production. In contrast, precipitation is risk-increasing and temperature is risk-decreasing in millet and sorghum production, respectively. 
Avowedly, several other factors such as genetic characteristics of seeds, solar radiation, soil moisture, pest invasion, fertilizer may also affect crop yields, especially in Sahel. However, time series data on the aforementioned variables for specific crop yield are not available.

The yield trends of the three major crops (Note 2) cultivated in Sahel are shown in Figure 1 below.

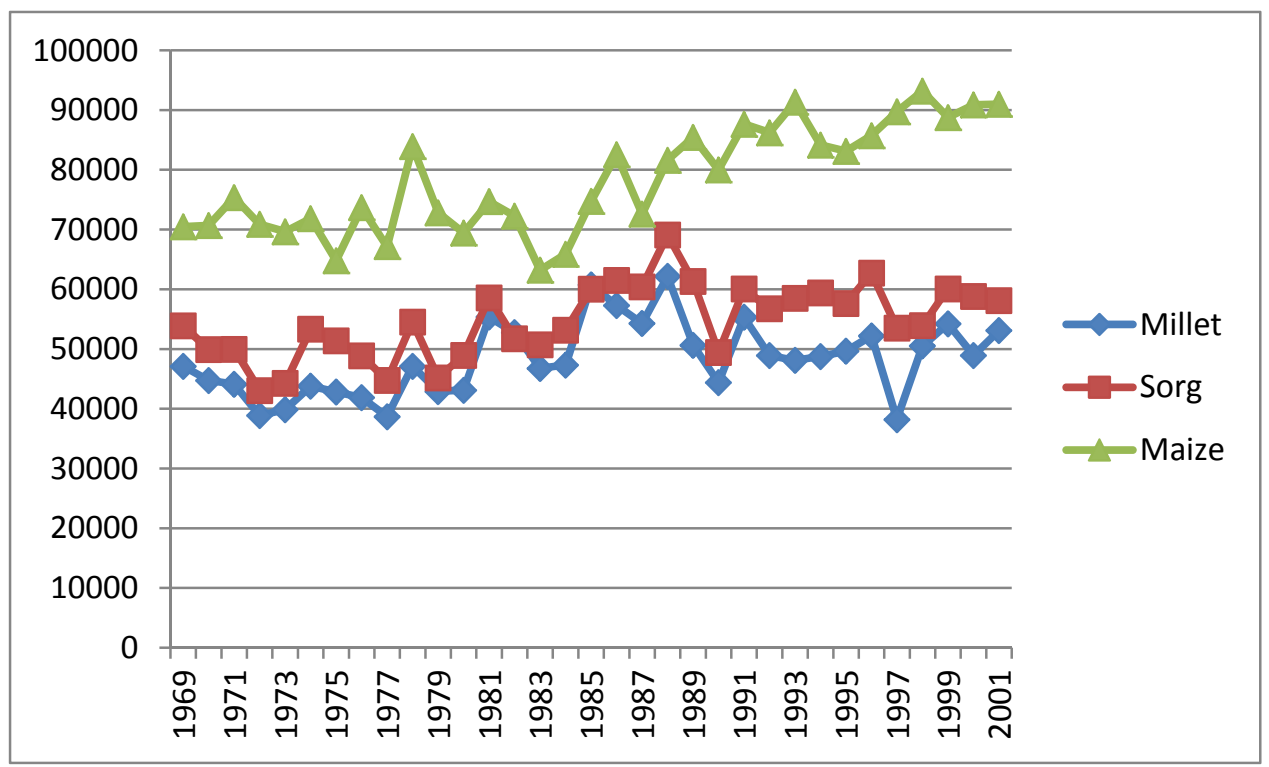

Figure 1. Average Crop yield by year in Sahel

The graph shows dramatic fluctuations with no significant upward trend, except for maize, suggesting a sluggish crop production in Sahel. Effort will be made to document the empirical evidence that would shed some light on the causes of the declining crop yields as illustrated in Figure 1. A number of previous studies have estimated the impacts of climatic change on the economy in general, and the agriculture sector in particular. Those impact studies have progressed in two directions. The first group uses simulation methods (Note 3) (Aggarwal and Mall, 2002; Mearns, Rosenzeig and Goldberg, 1997; Wang, 2005). As for the second group, regression models are estimated for specific crops (Chen, McCarl and Schimmelpfennig, 2004; Isik and Devadoss, 2006; McCarl, Villavicenio and $\mathrm{Wu}, 2008$ ), farmers' revenues (Deschenes and Greenstone, 2007) or land values (Mendelsohn, Nordhaus and Shaw, 1994). Until recently, the impact assessment studies mostly focused on the mean changes of crop yields and neglected the changes in variability (Mearns et al., 1997). Thus, the existence of little empirical evidence on crop yields due to climate variability has placed a strain on the information provided by the impacts of changes in temperature and precipitation. As a result, uncertainties still remain with regard to the estimates of the parameters of climate variables in yield production functions. Moreover, reliable information would also be useful in assessing mitigation policies. This paper will contribute to the existing literature by focusing on a drought-prone region in West Africa, and where the agriculture sector remains the main source of employment for more than 90 percent of the rural population (World Development Indicators). Commonly referred to as Sahel, the region has been the major locus of droughts during the past four decades. Moreover, in Sahel as it is the case in many African countries, on the average, less than 1 percent of cropland is irrigated. According to IPCC (2007), factors such as endemic poverty, bureaucracy, lack of physical and financial capital, frequent social unrest and ecosystem degradation significantly reinforce Africa's vulnerability to climate variability. Thus, a clear assessment of the effects of climate variability in a semi-arid zone is a handy policy tool. Although most African countries rely on agriculture to foster their economic growth (Barrios, Bazoumana and Strobl, 2008), the share of the sector in relation to GDP (gross domestic product) varies across countries. It ranges from $17.2 \%$ in Senegal to $62 \%$ in Guinea Bissau (World Bank, 2000). While Sahel's dependence on agriculture has been growing over time, evidence suggests that the productivity of the sector has declined (Sultan, Baron, Dingkuhn, Sarr and Janicot, 2005). Moreover, despite its large share of agricultural population, Sahel relies heavily on imports of foodstuffs, an ironic situation when compared to the United States where only $3 \%$ of the populations are farmers, but they provide up to $17.14 \%$ of the world production of cereals (FAOSTAT). Sahelian countries are in general agrarian 
economies; therefore, the study of the economic impacts of climate variability can be carried out through the agriculture sector without loss of generality.

The remaining of this paper is organized as follows: Section II discusses the data and the methodological framework. In section III, I analyze the empirical results. Finally, the concluding remark and policy implications follow in section IV.

\section{Data and Methods}

\subsection{Empirical Model}

The bulk of previous works on climate change either employs the crop simulation methods or uses the cross sectional hedonic approach and its variants to infer the magnitudes of the impacts. A critical examination of the merits of both methods used in analyzing the issue at hand raises some points of concern. The general circulation models (CGM), also known as the global climate models, are used to numerically simulate changes in climate resulting from changes in physical conditions such as greenhouse gases. However, critics argue that even a small change in atmospheric conditions is enough to cause the GCM to perform poorly.

The use of cross sectional model to predict the impacts of climate change is not exempt from criticism. For example, the Ricardian model pioneered by Mendelsohn et al. (1994) measures directly the impacts of climatic change on land value. Critics of this widely used method, Deschenes and Greenstone (2007), argue that omitted variables (e.g. the possibility to convert a land to a non-agricultural use) resulting from unobserved characteristics of land are key determinants of output and land value. Thus, the Ricardian model may produce some biased estimates. (Note 4) Change in land values may not accurately reflect change in climate conditions. Also, any aspects of future climates that differ from the present conditions will not be accounted for in the Ricardian model.

To capture how climate change and climate variability could hamper agricultural sector, a recent wave of studies looks at the effects of change in climate variables on crop yields. Along this line of thought, researchers such as Chen et al. (2004); Isik and Devadoss (2006) have used production risk, also known as stochastic production function developed by Just and Pop (JP) (1978).

The JP model is generally expressed in the following form:

$$
Y=f(X)+h(X)^{1 / 2} \epsilon, E(\epsilon)=0, V(\epsilon)=1 .
$$

Where $\mathrm{Y}$ is output, $\mathrm{X}$ is a vector of inputs, and $\mathrm{C}$ is a stochastic disturbance.

The idea behind the above specification is that the effects of inputs on output should not a priori be tied to the effects of inputs on the variability of output.

The first argument of equation (1) specifies the effects of inputs on the mean of output and the second argument expresses the effects of inputs on the variance of output.

Thus $\mathrm{E}(\mathrm{Y})=\mathrm{f}(\mathrm{X})$, and $\mathrm{V}(\mathrm{Y})=\mathrm{h}(\mathrm{X})$ and the two effects are independent.

For the purpose of this paper, I follow Isik and Devadoss (2006) and develop the following econometric model:

$$
\begin{aligned}
Y_{i j t}= & f\left(X_{i j t} ; \alpha\right)+\mu_{i t} \\
& \mu_{i t}=C_{i t} h\left(X_{i j t} ; \beta\right)^{1 / 2}
\end{aligned}
$$

Where $Y_{\mathrm{ijt}}$ is the $\mathrm{j}^{\text {th }}$ crop for country $i$ at year $\mathrm{t}$; $\mathrm{X}_{\mathrm{ijt}}$ is the $\mathrm{j}^{\text {th }}$ input used by country $\mathrm{i}$ at year $\mathrm{t}$; $\epsilon_{\mathrm{it}}$ is an error term with mean zero and variance equals to 1 to ensure positive output variance (Isik and Devadoss. 2006). $\alpha$ and $\beta$ are parameters to be estimated. Since the expected crop yield is

$$
E\left(Y_{i t}\right)=f\left(X_{i t} ; \alpha\right)
$$

and the variance of crop yield is given by:

$$
\mathrm{V}\left(\mathrm{Y}_{\mathrm{it}}\right)=\mathrm{V}\left(\mu_{\mathrm{it}} \mid \mathrm{X}\right)=\mathrm{V}\left(\epsilon_{\mathrm{it}}\right) * \operatorname{Exp}\left(\mathrm{h}\left(\mathrm{X}_{\mathrm{it}} ; \beta\right)\right)=\operatorname{Exp}\left(\mathrm{h}\left(\mathrm{X}_{\mathrm{it}} ; \beta\right)\right),
$$

then the estimates of $\alpha$ and $\beta$ give the effects of the independent variables on the mean crop yield and the variance of crop yields respectively.

The model expressed in the form of equation (2) has traditionally been estimated using either Feasible Generalized Least squares (FGLS) or maximum likelihood (ML) methods following Just and Pope $(1978,1979)$.

\subsubsection{The Feasible Generalized Least Squares Estimation (FGLS)}

The FGLS estimation is carried out using a three-step procedure. Firstly, from equation (2), $\mathrm{f}\left(\mathrm{X}_{\mathrm{ijt}} ; \alpha\right)$ is estimated via ordinary least squares. Secondly, the log of the squared residuals, $\hat{\mu}_{i}^{2}$ from the first step are used to obtain the 
estimates of parameters, $\hat{\beta}$, in the variability portion of the model in equation (2). Specifically, one should proceed as follows:

$$
\ln \left(\mu_{i t}^{2}\right)=\beta_{0}+h(x i, \beta)+\epsilon i
$$

Equation (5) can be consistently estimated by least squares (Saha, Havenner and Talpaz, 1997).

The third step is the weighted least squares estimation of the first argument in equation (2) using the antilog of the predicted value of the residuals obtained from the second stage as weight:

$$
y_{i}^{*}=f^{*}\left(x_{i}, \alpha\right)+\mu_{i}^{*}
$$

Where $y_{i}^{*}=y_{i} * \operatorname{Exp}\left(h\left(x_{i}, \widehat{\beta}^{-1 / 2}, f^{*}\left(x_{i}, \alpha\right)=f\left(x_{i}, \alpha\right) * \operatorname{Exp}\left(h\left(x_{i}, \widehat{\beta}^{-1 / 2}\right.\right.\right.\right.$, and $\mu_{i}^{*}=\mu_{\mathrm{i}} * \operatorname{Exp}\left(h\left(x_{i}, \widehat{\beta}^{-1 / 2}\right.\right.$

Amemiya (1985), and Jobson and Fueller (1980) (as cited in Saha et al., 1997) show that $\hat{\beta}$ and $\hat{\alpha}$ are consistent estimates.

2.1.2 The Maximum Likelihood Estimation (MLE)

Under the assumption $\epsilon_{\mathrm{it} t} \sim \mathrm{N}(0,1)$, the log-likelihood function of (2) is given by (Sala et al. 1997):

$$
\ln \mathrm{L}=-\frac{1}{2}\left[\mathrm{~N} * \ln (2 \pi)+\sum_{\mathrm{i}=1}^{\mathrm{n}} \frac{\left(\mathrm{y}_{\mathrm{ijt}}-\mathrm{f}\left(\mathrm{X}_{\mathrm{ijt}}, \alpha\right)\right) 2}{\exp \left(\mathrm{X}_{\mathrm{ijt}}, \beta\right)}+\sum_{\mathrm{i}=1}^{\mathrm{n}} \beta \mathrm{X}_{\mathrm{ijt}}\right]
$$

where $\mathrm{N}$ is the number of observations, $\mathrm{Y}$ and $\mathrm{X}$ are defined as above, and $\alpha$ and $\beta$ are unknown parameters to be estimated.

According to Saha et al. (1997), the maximum likelihood yields consistent and efficient parameter estimates of $\alpha$ and $\beta$.

I estimate the stochastic production function of maize, millet and sorghum yields using both the three-step FGLS and the single stage ML procedures of the linear and the quadratic forms of equation (2). However, using Monte Carlo experiments, Saha et al. (1997) present an appealing argument that, for small samples, ML estimates are unbiased and more efficient than the FGLS estimates. Thus, this paper will focus on MLE.

\subsection{Data and Descriptive Statistics}

This empirical study examines the impact of drought on the agricultural sector in eight countries of Sahel using data from 1970 to 2000 . These countries are of interest because they share similar climatic conditions and socio economic characteristics. The logic behind the choice of this starting date is supported by the idea that the noticeable decrease in precipitation in Sahel dates back to 1969 and precipitation time series data are not available beyond 2000. Three different crop yields are used as the dependent variables: maize, millet and sorghum. Those three are the main crops cultivated for subsistence in Sahel. Means, Maxima, minima and standard deviations of all the variables in the regressions are presented in Table 1. Crop yields are expressed in $\mathrm{kg} / \mathrm{ha}$. The variable temperature sends us two signals. First, the mean temperature is above $26^{\circ} \mathrm{C}$, which is quite high. Second, there is little difference between the high of 29.3 and the low of 21.3, indicating that Sahel is a very hot region. The aridity of the region is better portrayed by the precipitation variable which shows a large variability between the maximum and the minimum values. The descriptive statistics suggest that the observed variability in rain fall may well explain the tumbling agricultural productivity experienced by Sahelian countries since the beginning of 1970s.

Table 1. Descriptive statistics

\begin{tabular}{llllll}
\hline Variables & N & Mean & Standard Deviation & Maximum & Minimum \\
\hline Sorghum (kg/ha) & 248 & 6822 & 2595 & 16419 & 1256 \\
Millet (kg/ha) & 248 & 6026 & 2536 & 14829 & 1076 \\
Millet acreage (MTA) & 248 & 861326 & 1164813 & 5366055 & 1700 \\
Maize acreage (MZA) & 248 & 57117 & 71317 & 426300 & 936 \\
Sorghum acreage (SGA) & 248 & 489735 & 552979 & 2530518 & 5000 \\
Annual Precipitation (prec) & 248 & 554.36 & 385.94 & 1755.34 & 67.08 \\
$\quad(\mathrm{~mm})$ & & & & & \\
Average Temperature (Temp) (Celsius) & 248 & 26.75 & 1.41 & 29.34 & 21.33 \\
\hline
\end{tabular}


Droughts are recurrent and harsh in many African countries and especially in Sahel. The unpredictability of the rainfall combined with the aridity of the area predispose Sahel to be exceptionally vulnerable to the slightest decrease in precipitation or increase in temperature. All of the climate models predict a worldwide increase in temperature. And in Sahel, the increase in temperature is likely to be associated with a reduction in rainfall. The summer season is the only rainy season in the region. Precipitation data show an erratic rainfall pattern, with more trough than peak years. If the trend is to continue, then the region will likely see an increase in evapotranspiration, and therefore an increase in the severity and recurrence of droughts. Benson and Clay (1998) propose an economic definition of drought as "the impact of abnormally low rainfall, outside the normal expected parameters with which an economy is equipped to cope, on productive activities." Based on this definition, drought is an internal supply-side shock. This disturbance is caused by events outside the control of the affected country. And those events have significant impacts on all of the domestic economic sectors. To capture the adverse negative effects of droughts on agricultural productivity, I computed and used a 6-month SPI as a proxy for drought. This represents a significant departure from previous studies that used a total yearly precipitation or a drought-year dummy variable to analyze the economic impacts of climate change. (Note 5)

The SPI captures the severity of dry and wet spells. The index ranges from -4 to +4 , with values of 2 or greater denoting extremely wet spells and values of 2 or less indicating extremely dry spells. The condition is said to be near normal for SPI values between -0.99 to +0.99 .

The second climatic variable used in this study is temperature. The standard approach in agronomy suggests converting daily temperature into degree - days (Grierson, 2002; Deschenes and Greenstone, 2007). A logical explanation in support of this type of approach hinges on the idea that heat accumulation is beneficial to plants only when temperature is between a base of $8{ }^{\circ} \mathrm{C}$ and a ceiling of $32^{\circ} \mathrm{C}$ (Schlenker, Hanemann and Fischer, 2006). I use daily data on temperature to calculate growing season degree-days from June 1 to October 31 , as the region has only one growing season which coincides with the rainy season. Specifically, the variable temperature is calculated so that a day with an average temperature below 8 degrees $\mathrm{C}$ contributes to zero degree-days. If the average temperature is between 8 degrees $\mathrm{C}$ and 32 degrees $\mathrm{C}$, then the contribution to the degree-days is the difference between 32 and the number of degrees above 8 . Finally, for an average temperature above 32 , the contribution to the degree-days is 6.2 . The variable temperature is then calculated by summing the daily measures over the five months of the growing season. (Note 6)

The third climate variable used is the precipitation intensity variable, calculated as the ratio of total precipitation from the month with the highest value to the yearly total precipitation. This variable captures the temporal distribution of rainfalls. Values close to one indicate that rainfalls have been poorly spread out during the year.

The data on precipitation and temperature are taken from the Africa Rainfall and Temperature Evaluation System V1.0 (ARTES). Crops and acreage variables are derived from the FAOSTAT website.

\section{Regression Analysis}

Banerjee, Dolado, Galbraith and Hendry (1993) argue that (as cited in Chen et al., 2004) it may be possible for correlation to exist between time series variables even when they increase for different reasons. Therefore the correlation between the variables of interest will be spurious, which in turn will produce unreliable estimates. This spurious correlation between variables may be introduced through either deterministic or stochastic trend. To account for this possibility, I first run a panel data unit root test to the set of dependent and independent variables. The results are presented in Table 2. It appears from Table 2 that the variables are stationary as a panel, thus rejecting the hypothesis of a panel unit root, except for maize's acreage that must be first-differenced.

Table 2. Panel Unit Root Test

\begin{tabular}{llllllll}
\hline maize & millet & sorghum & MZA & MTA & SGA & Prec & Temp \\
\hline$-3.031^{\mathrm{a}}$ & $-5.466^{\mathrm{a}}$ & $-3.436^{\mathrm{a}}$ & -0.371 & $-2.645^{\mathrm{a}}$ & $-1.794^{\mathrm{b}}$ & $-5.403^{\mathrm{a}}$ & $-4.122^{\mathrm{a}}$ \\
\hline${ }^{\mathrm{a}}$ Null hypothesis of unit root is rejected with 99 percent confidence & & & & \\
\\
${ }^{\mathrm{b}}$ Null hypothesis of unit root is rejected with 95 percent confidence
\end{tabular}

After controlling for the time trend, I run the single stage ML estimations of linear and quadratic functional forms of equation (7). But the likelihood ratio tests favor the linear estimation. The Maximum Likelihood Estimation is carried out by fitting equation (7) for maize, millet, and sorghum yields. The results are summarized in Tables 3, 4 and 5 respectively. 


\subsection{Maize Yield Function}

The estimated coefficient for the degree-days variable is negative in the mean yield and positive in the variance equation, but not statistically significant in either case. These results are consistent with the hypothesis that an increase in temperature has no effect on maize production.

The SPI is positively related to the mean yield and yield variability of maize and statistically significant only in the mean function. The estimated coefficient in the mean function indicates that an increase in wet spells increases the mean of maize yield. Specifically, a one unit improvement in SPI is associated with a maize yield increase of about $503 \mathrm{~kg} / \mathrm{ha}$. Gambia and Guinea Bissau are the two largest producers of maize, and they are also relatively wetter countries compared to the remaining six. Thus the relatively higher precipitation in Guinea and Gambia seems to suit the production of maize in those regions. These results are in support of Chen et al. (2004) who find that corn has a greater water requirement and grows better in more temperate area. Also, Isik and Devadoss (2006) have found similar results for Idaho.

The precipitation intensity variable has a negative coefficient and is statistically significant at 1 percent level. This result indicates that a poor temporal spread of rainfall is harmful to crop. In fact, when the tendency is a shift toward greater intensity - precipitation is recorded during only one month (and the rest of the rainy season is dry), then the mean maize yield will decrease by $13275 \mathrm{~kg} / \mathrm{ha}$. The effects on crops of a poor rainfall spread seem to be more pronounced than the impact of drought. Of course, one may argue that a poor rainfall is also another form of agronomic drought. Thus, the two effects reinforce one another.

The estimated coefficient for the time trend lacks a statistical significance. This result is somewhat startling as I expected a technological improvement to increase the mean and reduce the variability of the maize yield. Probably, the time trend variable is picking up other factors besides the intended technological progress.

The positive sign of the acreage variable indicates that an increase in the cultivated area augments both the mean and the yield variability for maize. Although startling at first glance, the results with respect to acreage variable echo a report by ICRISAT (International Center for Research in the Semiarid Tropics) for noticing that maize yield has not kept up with the increase in the cultivated area that took place from the early 1970s to 2006 in Central and Western Africa. From Table 3, it appears that a 1 ha increase in acreage results in a modest $16.9 \mathrm{~g} / \mathrm{ha}$ increase in crop. In other words, extending the cultivated area will not help increase maize production.

Table 3. Impact of Temperature and Precipitation on Maize Yield in Sahel: MLE Results

\begin{tabular}{l|l|l}
\hline \multicolumn{2}{c}{ MAIZE } \\
\hline & Coefficients (T-ratios) & \multicolumn{1}{c}{ Coefficients (T-ratios) } \\
\hline \multirow{2}{*}{ Constant } & Mean Yield & Yield Variability \\
SPI & $13760(6.779)^{*}$ & $2718.3(2.363)^{* *}$ \\
Intensity & $502.61(1.721)^{* * *}$ & $30.283(0.151)$ \\
Degree-days & $-13275(-3.349)^{*}$ & $296.93(1.349)$ \\
Trend & $-206.98(-0.655)$ & $-26.68(-1.40)$ \\
Trend Squared & $31.572(0.3025)$ & \\
Acreage & $2.424(0.802)$ & $-0.0163(-8.576) *$ \\
R-square & $0.0169(5.343)^{*}$ & $7.65 \%$ \\
\cline { 2 - 3 } Log-likelihood Function & \multicolumn{2}{c}{-2374.57} \\
\hline
\end{tabular}

\section{Millet Yield Function}

With regards to the linear functional form, the estimated coefficients for the SPI, precipitation intensity and the time trend have a positive sign in the mean as well as the variance functions when applicable. On the other side, degree-days, acreage and time trend squared, all have a negative coefficient estimate. Furthermore, with the exception of the precipitation intensity, the estimated coefficients for the remaining variables are statistically significant. The positive sign of the drought index and the negative coefficient on the temperature variable suggest that change in climate variables should be of great concern to the populations of Sahel. Although millet is a heat-tolerant crop, a further increase in temperature will be detrimental to the production. The difference in magnitude in the effects of temperature and precipitation on the mean of millet yield is quite noticeable. In fact, a 
one unit increase in degree-days reduces millet yield by $170 \mathrm{~kg} / \mathrm{ha}$, while a one unit improvement in SPI increases millet yield by $451 \mathrm{~kg} / \mathrm{ha}$. It appears that drought is more detrimental to miller yield than higher temperature.

Also, my results show that a technological improvement augments the mean and the yield variability of millet. Table 4 reveals that a technological improvement will increase millet yield by an average of $128 \mathrm{~kg} / \mathrm{ha}$. The positive sign on the trend variable is consistent with the findings by Lusigi and Thirtle (1997) who study 47 African countries over the period 1961-1991 and conclude that R\&D expenditures play a key role in explaining the regain in productivity observed in the 1980s.

The estimated coefficient for the acreage variable is negative and statistically significant. Economically speaking, however, an increase in acreage has virtually no impact on millet yield. In fact, a 1 ha increase in acreage results in a reduction of millet yield of less than one-thousandth $(0.000697)$.

Table 4. Impact of Temperature and Precipitation on Millet Yield in Sahel: MLE Results

\begin{tabular}{l|l|l}
\hline \multicolumn{2}{|c}{ Millet } \\
\hline & Coefficients (T-ratios) & Coefficients (T-ratios) \\
\hline Constant & Mean Yield & Yield Variability \\
SPI & $6278.2(8.664)^{*}$ & $2718.3(2.363)^{* *}$ \\
Intensity & $451.06(5.676)^{*}$ & $117.75(2.119)^{* *}$ \\
Degree-days & $239.21(0.173)$ & \\
Trend & $-170.51(-1.924)^{* * *}$ & $-98.249(-2.083)^{* *}$ \\
Trend Squared & $128.06(3.919)^{*}$ & $36.582(4.14)^{*}$ \\
Acreage & $-2.467(-2.802)^{*}$ & \\
R-square & $-0.000697(-13.09)^{*}$ & $-0.000572(-15.87)^{*}$ \\
\cline { 2 - 3 } Log-likelihood Function & \multicolumn{2}{|c}{$13.65 \%$} \\
\hline
\end{tabular}

\subsection{Sorghum Yield Function}

The estimated coefficients for the SPI and the time trend are statistically significant and have positive effects on the mean of the sorghum yield function. Simultaneously, the estimated equation for sorghum indicates that the degree-days, the precipitation intensity and the acreage variables tend to decrease the mean and the variance of the sorghum yield. Specifically, the estimated coefficient for SPI indicates that a 1 unit improvement in drought index increases sorghum yield by $634 \mathrm{~kg} / \mathrm{ha}$. As for temperature, the magnitude of the effect is comparable to that of precipitation. A unit increase in degree-days reduces sorghum yield by $664 \mathrm{~kg} / \mathrm{ha}$. Precipitation intensity appears to have the most pronounced effect on sorghum yield. When precipitation is recorded only during one month of the rainy season, sorghum yield significantly decreases by $9765 \mathrm{~kg} / \mathrm{ha}$.

With respect to the sign of the coefficients, McCarl et al. (2008) find similar results for the U.S., except that their coefficients were more often statistically insignificant.

The production of sorghum is almost equally spread throughout the region and on a global scale, Sahel is a dry area. Therefore, the results confirm my expectation that higher temperatures are harmful, while more rainfall is beneficial to sorghum. With sorghum, unlike millet, the impact of temperature and precipitation is almost identical in terms of magnitude.

The sign on the coefficient for degree-days and precipitation intensity corroborates the findings by McCarl et al. (2008) of the damaging effects of more extreme events as a result of climate change. 
Table 5. Impact of Temperature and Precipitation on Sorghum Yield in Sahel: MLE Results

\begin{tabular}{l|l|l}
\hline \multicolumn{2}{c}{ Sorghum } \\
\hline & Coefficients (T-ratios) & Coefficients (T-ratios) \\
\hline Constant & Mean Yield & Yield Variability \\
SPI & $13175(12.75)^{*}$ & $2718.3(2.363)^{* *}$ \\
Intensity & $634.17(4.04)^{*}$ & $114.90(1.057)$ \\
Degree-days & $-9765.1(-4.688)^{*}$ & \\
Trend & $-664.31(-3.957)^{*}$ & $-382.27(-3.318)^{*}$ \\
Trend Squared & $161.13(2.929)^{*}$ & $-4.2013(-0.394)$ \\
Acreage & $-3.0937(-1.87)^{* * *}$ & \\
R-square & $-0.00287(-18.81)^{*}$ & $-0.000633(-6.056)^{*}$ \\
\cline { 2 - 3 } Log-likelihood Function & \multicolumn{2}{|c}{} \\
\hline
\end{tabular}

\section{Conclusion}

This paper presents empirical estimates of the effects of a constructed index of degree-days, precipitation intensity index, and a standardized precipitation index (SPI) on the mean yield and yield variability of three major crops in eight countries in the Sahelian region. I use a Just-Pope stochastic production function of maize, millet and sorghum for the period spanning 1970 to 2000 . The results suggest that changes in climate variables show a similar pattern across all of the three major crops cultivated in Sahel. Specifically, while an increase in the degree-days tends to be harmful to crop yields, SPI and precipitation intensity index have statistically positive impacts on the mean crop yields. In contrast, the sign of the estimates for acreage variable is crop specific. Finally, technological improvement is consistently found to be associated with an increase in the mean yields. In sum, the results suggest that changes in temperature and precipitation are risk-increasing.

These results are robust not only to several alternative functional specifications, but to different estimation techniques as well.

The results of this study have implications in farmers' decision to allocate agricultural land because the effects of acreage are found to be crop specific. The coefficient on the acreage variable has a positive sign in the maize yield equation, but negative in the millet yield and sorghum yield equations. In addition, there are better ways of helping rural population by giving them more access to irrigation as the bulk of rainfall is received during one month, and this paper documents that a poor rainfall spread is damaging to crop yields.

\section{References}

Amemiya, T. (1985). Advanced Econometrics. Cambridge, MA: Harvard University Press.

Aggarwal, P. K., \& Mall, R. K. (2002). Climate Change and Rice Yields in Diverse Agro-Environment of India: Effects of Uncertainties in Scenarios and Crop Models on Impact Assessment. Climatic Change, 52, 331-343. http://dx.doi.org/10.1023/A:1013714506779

Banerjee, A., Dolado, J., Galbraith, J. W., \& Hendry, D. F. (1993). Co-integration, Error Correction, and the Econometric Analysis of Non-stationary Data. New York, NY: Oxford University Press Inc.

Barrios, S., Bazoumana, O., \& Strobl, E. (2008). The impact of climatic change on agricultural production: Is it different for Africa? Food Policy, 33, 287-298. http://dx.doi.org/10.1016/j.foodpol.2008.01.003

Benson, C., \& E. Clay. (1998). The Impact of Drought on Sub-Saharan African Economies: A Preliminary Examination. Washington, DC: World Bank, Technical Paper No. 401.

Boko, M., Niang, I., Nyong, A., Vogel, C., Githeko, A., Medany, M., Osman-Elasha, B., Tabo, R., \& Yanda, P. (2007). Africa. Climate Change 2007: Impacts, Adaptation and Vulnerability. In M.L. Parry, O.F. Canziani, J.P. Palutikof, P.J. van der Linden \& C.E. Hanson (Eds.), Contribution of Working Group II to the Fourth Assessment Report of the Intergovernmental Panel on Climate Change (pp. 433-467). Cambridge, England: Cambridge University Press.

Chen, C., McCarl, B. A., \& Schimmelpfennig, D. E. (2004). Yield Variability as Influenced by Climate: A Statistical Investigation.

Climatic

Change,

$6(1-2)$, 239-261. http://dx.doi.org/10.1023/B:CLIM.0000043159.33816.e5 
Deschenes, O., \& Michael, G. (2007). The Economic Impacts of Climate Change: Evidence from Agricultural Output and Random Fluctuations in Weather. American Economic Review, 97(1), 354-385. http://dx.doi.org/10.1257/aer.97.1.354

Food and Agricultural Organization of the United Nations- FAOSTAT. (2008). Internet site: http://apps.fao.org/page/collections?subset=agriculture (Accessed December 7).

Grierson, W. (2002). Role of Temperature in the Physiology of Crop Plants: Pre- and Post-Harvest. In M. Pessarakli (Eds.), Handbook of Plant and Crop Physiology, 13-34. New York, NY: Marcel Dekker. http://dx.doi.org/10.1201/9780203908426.ch2

Houghton, J. T., Meiro-Filho, L. G., Callandar, B. A., Harris, N., Kattenburg, A., \& Maskell, K. (Eds.). (1996). Climate Change 1995: The Science of Climate Change. Cambridge, England: Cambridge University Press.

Isik, M., \& Devadoss, S. (2006). An Analysis of the Impact of Climate Change on Crop Yields and Yield Variability. Applied Economics, 38, 835-844. http://dx.doi.org/10.1080/00036840500193682

Jobson, J. D., \& Fuller, W. A. (1980). Least Squares Estimation When the Covariance Matrix and Parameter Vector are Functionally Related. Journal of the American Statistical Association, 75, 176-181. http://dx.doi.org/10.1080/01621459.1980.10477450

Just, R. E., \& Pope, R. D. (1979). Production Function Estimation and Related Risk Considerations. American Journal of Agricultural Economics, 61, 276-284. http://dx.doi.org/10.2307/1239732

Just, R. E., \& Pope, R. D. (1978). Stochastic Specification of Production Function and Economic Implications. Journal of Econometrics, 7, 67-76. http://dx.doi.org/10.1016/0304-4076(78)90006-4

Lusigi, A., \& Thirtle, C. (1997). Total Factor Productivity and the Effects of R\&D in African Agriculture. Journal of International Development, $9, \quad 529-538$. http://dx.doi.org/10.1002/(SICI)1099-1328(199706)9:4<529::AID-JID462>3.0.CO;2-U

McCarl, B. A., Villavicenio, X., \& Wu, X. (2008). Climate Change and Future Analysis: Is Stationarity Dying? $\begin{array}{llll}\text { American Journal of Agricultural Economics, } & \text { 90, }\end{array}$ http://dx.doi.org/10.1111/j.1467-8276.2008.01211.x

Mearns, L. O., Rosenzeig, C., \& Goldberg, R. (1997). Mean and Variance Change in Climate Scenarios: Methods, Agricultural Application, and Measures of Uncertainty. Climatic Change, 35, 367-396. http://dx.doi.org/10.1023/A:1005358130291

Mendelsohn, R., Nordhaus, W. D., \& Shaw, D. (1994). The Impact of Global Warming on Agriculture: A Ricardian Analysis. American Economic Review. 84, 753-771.

Saha, A., Havenner, A., \& Talpaz, H. (1997). Stochastic Production Function Estimation: Small Sample Properties of ML versus FGLS. Applied Economics, 29, 459-469. http://dx.doi.org/10.1080/000368497326958

Schimmelpfennig, D. E., \& Yohe, G. (1999). Vulnerability of Agricultural Crops to Climate Change: A Practical Method of Indexing. In G. Frisvold \& B. Kuhn (Eds.), Global Environmental Change and Agriculture: Assessing the Impacts, 193-217. Northampton, MA: Edward Elgar Publishing Limited.

Schlenker, W., Hanemann, W. M., \& Fisher, A. C. (2006). The Impact of Global Warming on U.S. Agriculture: An Econometric Analysis of Optimal Growing Conditions. Review of Economics and Statistics, 88(1), 113-125. http://dx.doi.org/10.1162/rest.2006.88.1.113

Solomon, S., Quin, D., Manning, M., Chen, Z., Marquis, M., Avertyt, K., Tignor, M., \& Miller, H. (Eds.). (2007). Climate Change 2007: The Physical Science Basis. Contribution of Working Group 1 to the Fourth Assessment Report of the Intergovernmental Panel on Climate Change. New York, NY and Cambridge, England: Cambridge University Press.

Sultan, B., Baron, C., Dingkuhn, M., Sarr, B., \& Janicot, S. (2005). Agricultural impacts of large-scale variability of the West African monsoon. Agriculture \& Forest Meteorology, 128(1/2), 93-110. http://dx.doi.org/10.1016/j.agrformet.2004.08.005

Thiele, R. (2003). Price Incentives, Non-Price Factors and Agricultural Production in Sub Saharan Africa: A Cointegration Analysis. African Development Review, 15, 425-438. http://dx.doi.org/10.1111/j.1467-8268.2003.00079.x

Wang, G. (2005). Agricultural Drought in a Future Climate: Results From 15 Global Climate Models Participating in the IPCC 4th assessment. Climate Dynamics, 25, 739-753. http://dx.doi.org/10.1007/s00382-005-0057-9 


\section{Notes}

Note 1. This is an improvement over previous studies that used mean annual temperature and average precipitation as their climate variables.

Note 2. Sahel's agriculture is dualistic, with millet, maize and sorghum destined for subsistence and cotton and groundnuts being the cash crops (Thiele, 2003).

Note 3. See Wang, 2005 for an extensive review of literature of the studies using a simulation method to investigate the effects of climate change on crop yields.

Note 4. To all fairness, see Deschenes and Greenstone (2007) who pointed out some advantages as well as the disadvantages of both methods.

Note 5. To capture the impacts of weather variability, past studies employed two climate variables, namely temperature and precipitation.

The average annual temperature (Isik and Devadoss, 2006) or the number of growing degree days (Ritchie et al. 1991,) have been used as a proxy for change in temperature. And the variability in precipitations was captured using the average annual precipitation or cumulative annual precipitation (Pradeep and Mandelsohn, 1996).

Note 6. I use interchangeably growing season and rainy season because farmers grow millet and sorghum only during the rainy season. 